\title{
Mechanistic Investigation on Ethanol to Butadiene Conversion Reaction over Metal Oxide Clusters: A Computational Study
}

\author{
Valeria Butera $^{1}$, Yusuke Tanabe ${ }^{2}$, Yu Shinke ${ }^{2}$, Tomohisa Miyazawa ${ }^{1}$, Tadahiro Fujitani ${ }^{1}$, \\ Megumi Kayanuma ${ }^{1}$, and Yoong-Kee Choe $^{1}$ \\ ${ }^{1}$ Sangyo Gijutsu Sogo Kenkyujo Tsukuba \\ ${ }^{2}$ Research Association of High-Throughput Design and Development for Advanced \\ Functional Materials
}

August 11, 2020

\begin{abstract}
Density functional theory (DFT) calculations were conducted to investigate mechanistic details of ethanol-to-butadiene conversion reaction over $\mathrm{MgO}$ or $\mathrm{ZnO}$ catalyst. We evaluated the Lewis acidity and basicity of $\mathrm{MgO}$ and $\mathrm{ZnO}$ and found that $\mathrm{ZnO}$ had the stronger Lewis acidity and basicity compared with those of MgO. Potential energy surfaces (PESs) of ethanol-to-butadiene conversion, which included relevant transition states (TSs) and intermediates, were computed in detail following the generally accepted mechanism reported in the literature, where such mechanism included ethanol dehydrogenation, aldol condensation, Meerwein-Pondorf-Verley (MPV) reduction and crotyl alcohol dehydration. DFT results showed that ethanol dehydrogenation was the rate limiting step of overall reaction when the reaction was catalyzed by MgO. Also, DFT results showed that ethanol dehydrogenation occurred more easily on $\mathrm{ZnO}$ compared with $\mathrm{MgO}$ where such a result correlated with the stronger Lewis acidity of $\mathrm{ZnO}$. In addition, we computed ethanol dehydration which generates ethylene, one of the major undesired side reaction products for butadiene formation. DFT results showed that $\mathrm{ZnO}$ favored dehydrogenation over dehydration while MgO favored dehydration.
\end{abstract}

\section{Introduction}

Butadiene is one of the most important bulk chemicals produced in the petrochemical industry. For instance, it is used as a monomeric compound for synthetic rubber. Currently, butadiene is mainly obtained from petrochemical sources, as a byproduct of the naphtha steam cracking process during ethylene production. ${ }^{[1]}$ Development of a cheap and sustainable process for its production from biomass-based resources would result in reduced reliance on oil resources. In this context, the possible catalytic conversion of ethanol-to-butadiene has attracted much interest. Obviously, the choice of catalysts has a strong effect on the rate of butadiene formation, selectivity, and yield. As such, many different catalysts have been explored in recent years. ${ }^{[2-10]}$ Among them, the $\mathrm{MgO} / \mathrm{SiO}_{2}$ catalyst has been widely studied.[6]

Baltrusaitis et al. investigated the structure and reactivity of $\mathrm{MgO} / \mathrm{SiO}_{2}$ focusing on the role of weak and strong basic and acidic sites on the surface. ${ }^{[6]}$ Zhang et al. have studied the structural and surface properties of $\mathrm{MgO} / \mathrm{SiO}_{2}$ by both experimental characterization and simulation. ${ }^{[7]}$ Their X-ray analysis results showed that $\mathrm{MgO}$ and $\mathrm{SiO}_{2}$ maintain their native morphology, and phases corresponding to $\mathrm{MgSiO}_{4}$ were not observed. Based on such observations, they concluded that the role of $\mathrm{SiO}_{2}$ in $\mathrm{MgO} / \mathrm{SiO}_{2}$ is to increase the structural defects of $\mathrm{MgO}$ and, thereby, the catalytic activity. Niiyamaet al. examined the correlation between acidity/basicity and $\mathrm{MgO} / \mathrm{SiO}_{2}$ activity ${ }^{[11]}$ and reported that butadiene formation includes dehydrogenation and dehydration reactions, where the former takes place on basic sites and the latter on acidic sites, suggesting the importance of both site types for butadiene yield. 
Regarding the reaction mechanism, because of its intrinsically complex nature, several mechanisms have been proposed. ${ }^{[12-19]}$ At present, the mechanism described in Scheme 1 is generally accepted. This mechanism indicates that two acetaldehyde molecules are formed as a consequence of dehydrogenation of ethanol. Subsequently, an aldol condensation reaction occurs leading to the formation of 3-hydroxybutanal. Dehydration of 3-hydroxybutanal produces crotonaldehyde, which is further hydrogenated and dehydrated to form the final product, butadiene. Although many researchers ${ }^{[20-28]}$ have subsequently adopted the general features of this mechanism, different suggestions have been proposed as to what constitutes the rate-determining step in the reaction. Many undesired processes can also occur leading to the production of different byproducts such as butanol, carbon dioxide and ethylene.

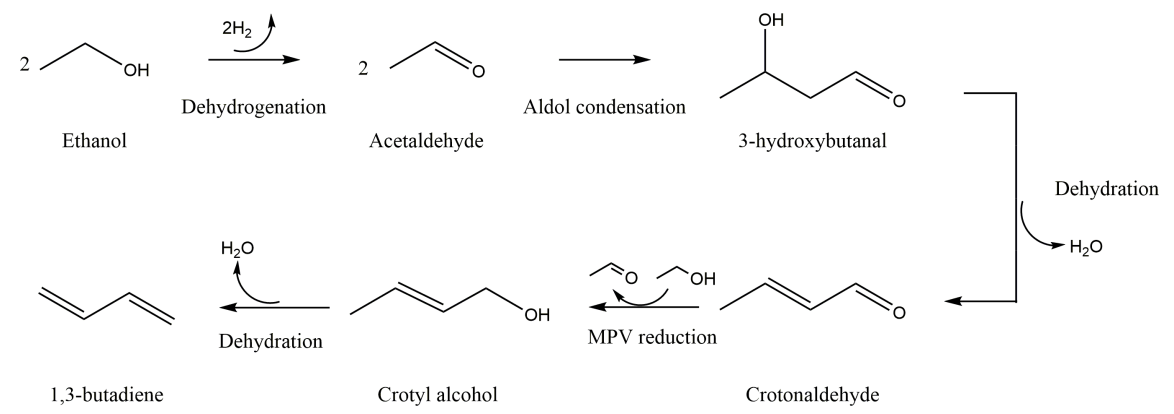

Scheme 1. Reaction mechanism on the conversion of ethanol into 1,3-butadiene.

A number of computational studies on the reaction mechanism of ethanol-to-butadiene conversion have been reported..$^{[7,25-28]}$ For examples, Chieregatoet al. performed a computational modeling coupled with an experimental study on a $\mathrm{MgO}$ cluster to investigate the reactivity of ethanol. ${ }^{[24]}$ As a model for $\mathrm{MgO}$ nanocrystals, $(\mathrm{MgO})_{10}$ or $(\mathrm{MgO})_{16}$ clusters were used. They suggested that, based on their experimental and computational results, crotyl alcohol and 3-buten-1-ol are the key intermediates and precursors for butadiene formation. Zhang et al. carried out a periodic DFT study on the aldol condensation reaction on MgO. ${ }^{[25]}$ According to their results, the barrier height of the C-C coupling step in the aldol condensation reaction was computed to be lower than the proton transfer step. Baltrusaitiset al. also used periodic DFT methods to explore the ethanol-to-butadiene reaction mechanism. ${ }^{[26]}$

To improve catalytic performance, a mixture of metal oxides has been suggested. ${ }^{[3,29]}$ The introduction of $\mathrm{ZnO}$ has been reported to enhance the catalytic performance of $\mathrm{MgO} / \mathrm{SiO}_{2}{ }^{[4]}$, which is of interest for investigating details of the performance at the molecular level. There have been several computational mechanistic studies on some metal oxides such as $\mathrm{MgO},{ }^{[25,26]} \mathrm{ZrO}_{2},{ }^{[27]} \mathrm{Zr}-\mathrm{SBA}-15^{[28]}$, but to our knowledge, no study has dealt with a detailed computational investigation on full mechanistic aspects described in Scheme 1. Moreover, the atomistic mechanism on the enhanced catalytic performance by $\mathrm{ZnO}$ as a catalyst for the ethanol-to-butadiene conversion has still been elusive. In designing new catalysts for ethanol-tobutadiene conversion, inhibition of undesired side reactions is very important; ${ }^{[1]}$ however, no study on the reaction mechanisms of the side reactions at the molecular level has been reported. Thus, in the present paper, we report results of our computational investigation on each step of the complex reaction conversion of ethanol to butadiene catalyzed by $\mathrm{MgO}$ or $\mathrm{ZnO}$, to understand how the different acidic and basic properties of catalysts affect the reaction mechanism. In addition to the main reaction, we consider also a side reaction leading to the formation of ethylene by the dehydration of ethanol.

\section{Computational Details}

\section{Catalyst modeling}

Recent studies suggest that mesoporous silica is a good catalyst support for metal oxide catalysts. ${ }^{[30]}$ Obviously, in mesoporous silica, the metal oxide catalyst exits as a nanocluster. Thus, considering computational cost and accuracy, in the present study, catalysts were modeled as ultrasmall nanoclusters. For MgO, we 
adopted the structure reported in the literature. ${ }^{[31]}$ For the $\mathrm{ZnO}$ cluster model, we replaced the $\mathrm{Mg}$ atoms of the $(\mathrm{MgO})_{16}$ cluster by $\mathrm{Zn}$ atoms and performed geometry optimization; the optimized structure is shown in Fig. 1 alongside that of $(\mathrm{MgO})_{16}$.

\section{Hosted file}

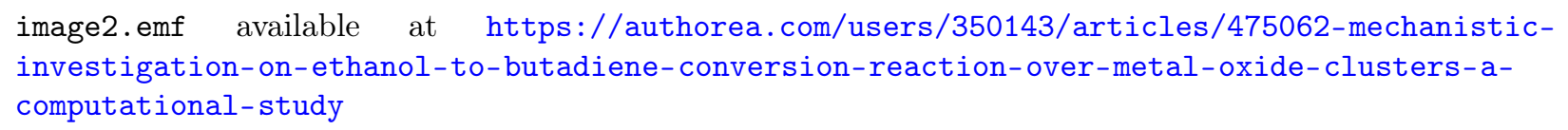

Figure 1. $(\mathrm{MgO})_{16}$ and $(\mathrm{ZnO})_{16}$ cluster models. (Color description $\mathrm{Mg}$ : yellow; O: red; $\mathrm{Zn:} \mathrm{cyan)}$

As shown in Fig. 1, the optimized structure of the $(\mathrm{ZnO})_{16}$ cluster exhibits a feature similar to those of $(\mathrm{MgO})_{16}$. Vibrational frequency calculation confirms that the structure of $(\mathrm{ZnO})_{16}$ (Fig. 1) corresponds to the potential energy minimum. To check the possibility of other minima structures of $(\mathrm{ZnO})_{16}$, we further applied one of the global optimization algorithms ${ }^{[32]}$ implemented in the atomic simulation environment (ASE) program. ${ }^{[3,34]}$ The result of the global optimization indicates that the structure shown in Fig. 1 is a global minima.

\section{Details of DFT calculations}

Geometry optimizations and frequency calculations for all reactants, intermediates, products, and transition states (TSs), were performed using DFT, as implemented in the Gaussian 16 quantum chemistry package. ${ }^{[35]}$ We selected the B3LYP functional, ${ }^{[36,37,38,39]}$ which combines Becke's 1988 exchange functional with the correlation functional by Lee, Yang, and Parr.

As for the basis sets, the full-electron basis set 6-311G** for $\mathrm{O}, \mathrm{H}, \mathrm{C}, \mathrm{Mg}$ and $\mathrm{Zn}$ atoms was chosen. After geometry optimization calculations, vibrational frequency calculations were conducted to check the nature of stationary points on potential energy surfaces (minima or TS). Intrinsic reaction coordinate (IRC) calculations ${ }^{[40]}$ were performed to confirm the obtained reactant and product connected through the TS.

\section{Results and Discussion}

Because of its complexity, the overall reaction mechanism was divided into 4 different parts leading to the formation of 1) acetaldehyde; 2) crotonaldehyde; 3) crotyl alcohol; and 4) butadiene. Each part will be discussed separately in this section.

\section{Acidity and basicity of clusters}

The catalytic behavior of metal oxides is related to the fact that their surface has both Lewis acidic (metal atoms) and basic sites (oxygen atoms). ${ }^{[41]}$ In experiments, the acidity or basicity strength of the surface is typically examined using probe molecules such as $\mathrm{CO}_{2}$ (adsorbed on a basic site), or $\mathrm{NH}_{3}$ (adsorbed on an acidic site). ${ }^{[42]}$ Thus, to understand the cluster's intrinsic basic or acidic nature, we first investigated the adsorption energy of $\mathrm{CO}_{2}$ or $\mathrm{NH}_{3}$ on the metal oxide clusters where the adsorption energy $(E$ ads $)$ is defined as follows:

$E_{\text {ads }}=E_{\text {ads }+\mathrm{c}}-E_{\mathrm{c}}-E_{\text {adsorbate }}$

$E$ abs+c indicates the energy of the cluster adsorbed by the adsorbate molecule, $E_{\mathrm{c}}$ indicates the energy of the bare cluster and $E$ adsourbateindicates the energy of adsorbate molecule.

The results of the optimized structures of the metal oxide clusters adsorbed by the probe molecule are presented in Fig. 2. 

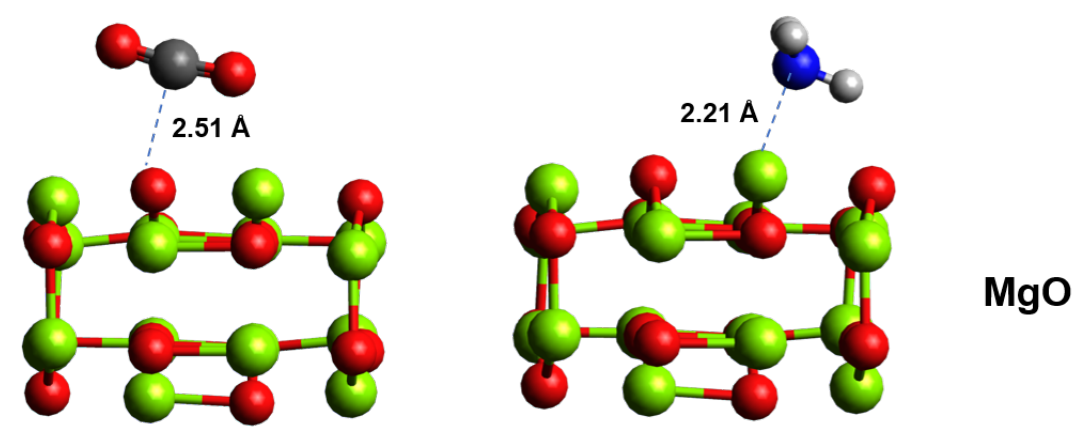

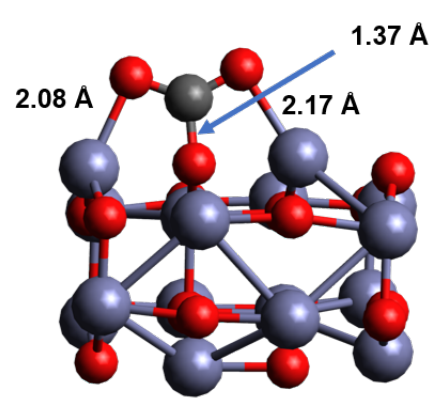

(a)

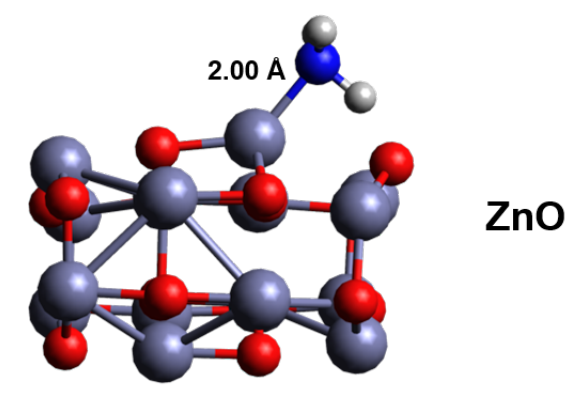

(b)

Figure. 2 . Optimized structures of probe molecules ((a) $\mathrm{CO}_{2}$, (b) $\left.\mathrm{NH}_{3}\right)$ adsorbed on $\mathrm{MgO}$ or $\mathrm{ZnO}$ clusters. (Color description Mg: green; O: red; Zn: cyan; C: grey, H: white, N: blue)

For $\mathrm{MgO}$, the distance between the $\mathrm{C}$ atom of $\mathrm{CO}_{2}$ and one of the $\mathrm{O}$ atoms of the $\mathrm{MgO}$ cluster was computed to be $2.51 \AA$ and $E$ ads was computed to be $-7.8 \mathrm{kcal} / \mathrm{mol}$ where the (-) sign indicates net stabilization upon the complex formation. For $\mathrm{ZnO}$, the figure indicates that $\mathrm{CO}_{2}$ interacts more strongly with the metal oxide, which is manifested by the short distance $(1.37 \AA)$ between the $\mathrm{C}$ atom of $\mathrm{CO}_{2}$ and one of the $\mathrm{O}$ atoms of the $\mathrm{ZnO}$ cluster. The resulting $E$ ads was computed to be $-36.8 \mathrm{kcal} / \mathrm{mol}$, which indicates that $\mathrm{CO}_{2}$ is chemically adsorbed. Moreover, it is seen in the figure that the distances between the $\mathrm{Zn}$ atom and the two $\mathrm{O}$ atoms of $\mathrm{CO}_{2}$ are around $2.1 \AA$, implying that, in addition to the $\mathrm{C}$ atom, the two $\mathrm{O}$ atoms interact with the cluster. Such a structure is similar to the tridentate configuration of chemically absorbed $\mathrm{CO}_{2}$ on a Zn (0001) surface. ${ }^{[43]}$ Also, the above trend is in accordance with a result of a microcalorimetric study by Auroux et al. , where they reported that the order of basicity of pure metal oxide surfaces is $\mathrm{ZnO}>\mathrm{MgO} .{ }^{[44]}$ In Fig. 2 (b), the optimized structure of metal oxides with $\mathrm{NH}_{3}$ is presented. As shown, the distance between the Lewis acidic site (the metal atom) of the cluster with the $\mathrm{N}$ atom of $\mathrm{NH}_{3}$ was computed to be 2.21 and $2.00 \AA$ for $\mathrm{MgO}$ and $\mathrm{ZnO}$ clusters, respectively. A corresponding $E$ ads value for $\mathrm{ZnO}$ was computed to be $-27.3 \mathrm{kcal} / \mathrm{mol}$, which is, again, larger than that of $\mathrm{MgO}(-21.5 \mathrm{kcal} / \mathrm{mol})$. Thus, DFT result indicates that the Lewis acidity of $\mathrm{ZnO}$ is stronger than that of $\mathrm{MgO}$.

\section{Ethanol adsorption}

A very first part of the overall mechanism is the conversion of ethanol into acetaldehyde, which starts with the adsorption of ethanol on the cluster. Ethanol adsorption on the MgO surface was investigated by Branda et al.$^{[45]}$ using an embedded cluster model approach. The authors considered four different absorption sites: terrace, edge, O-apical, and Mg-apical; their positions on the $\mathrm{MgO}$ (100) surface are described in Fig. 3. According to their results, the absorption energy becomes stronger in the following order: terrace $<$ edge $<$ 
O-apical $<$ Mg-apical.

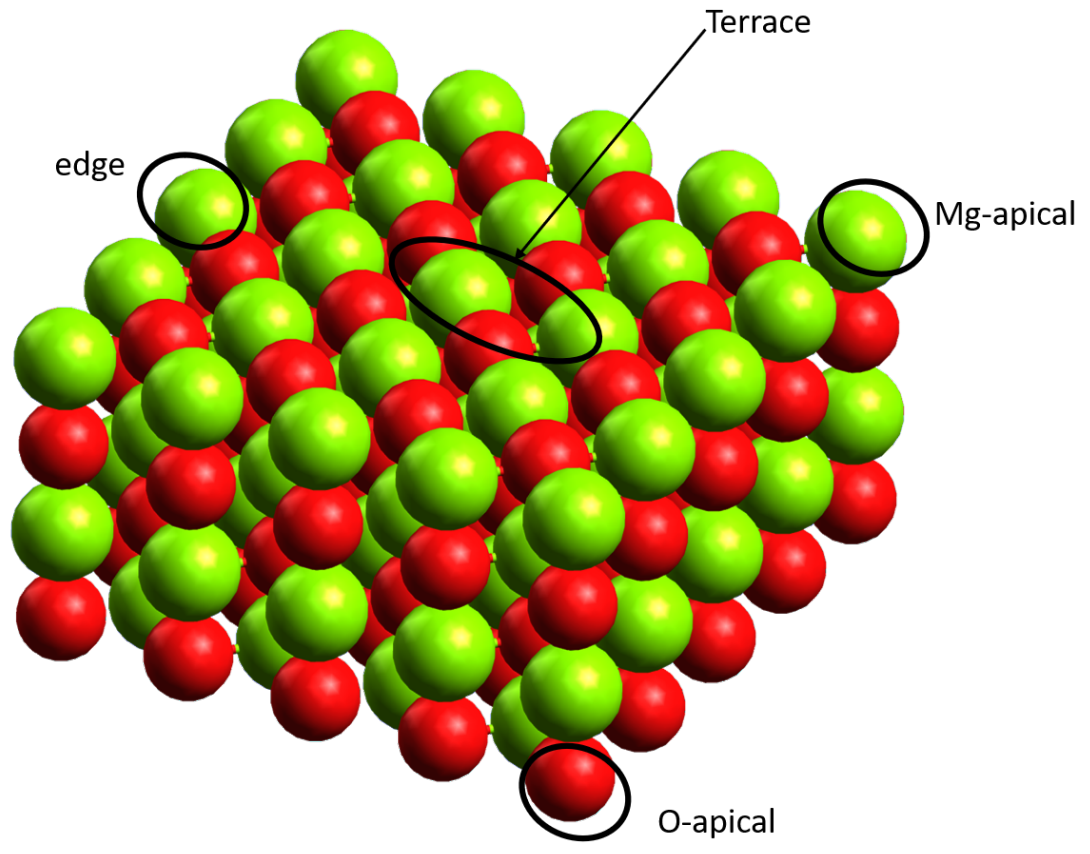

Figure 3. Four different sites of the $\mathrm{MgO}(100)$ surface.

Branda et al. ${ }^{[45]}$ found that dissociative adsorption occurs at the sites with defects (edge and apical) resulting in the consequent $\mathrm{H}$ transfer from the $\mathrm{OH}$ group in ethanol to the $\mathrm{O}$ atom of the $\mathrm{MgO}$ surface. However, when ethanol is adsorbed on the surface without defects (terrace) two bonds are formed: 1) a hydrogen bond between the $\mathrm{H}$ of the ethanol molecule and an $\mathrm{O}$ of the surface; and 2) an interaction between a $\mathrm{Mg}$ atom of the surface and the $\mathrm{O}$ of ethanol. In the present study, we also considered terrace and $\mathrm{O}$ - and $\mathrm{Mg}$ apical ethanol adsorption. In agreement with the result of Branda et al.,$^{[45]}$ we found that nondissociative adsorption of ethanol occurs on the terrace site. However, the adsorption of ethanol molecule on the apical sites is dissociative only in the $\mathrm{O}$-apical case while no ethanol dissociation occurs when ethanol is adsorbed on the Mg-apical site. The computed absorption energies $\left(E_{\text {ads }}\right)$ are $-21.0,-29.0$ and $-37.9 \mathrm{kcal} / \mathrm{mol}$ for the terrace, Mg-apical, and O-apical sites, respectively.

\section{Ethanol dehydrogenation}

As described in Scheme 1, the first part of ethanol-to-butadiene conversion reaction is the dehydrogenation reaction of ethanol to form acetaldehyde. Fig. 4 shows PESs of the dehydrogenation reaction catalyzed by $\mathrm{MgO}$ or $\mathrm{ZnO}$, also including the schematic representations of all the intermediates and TSs. 

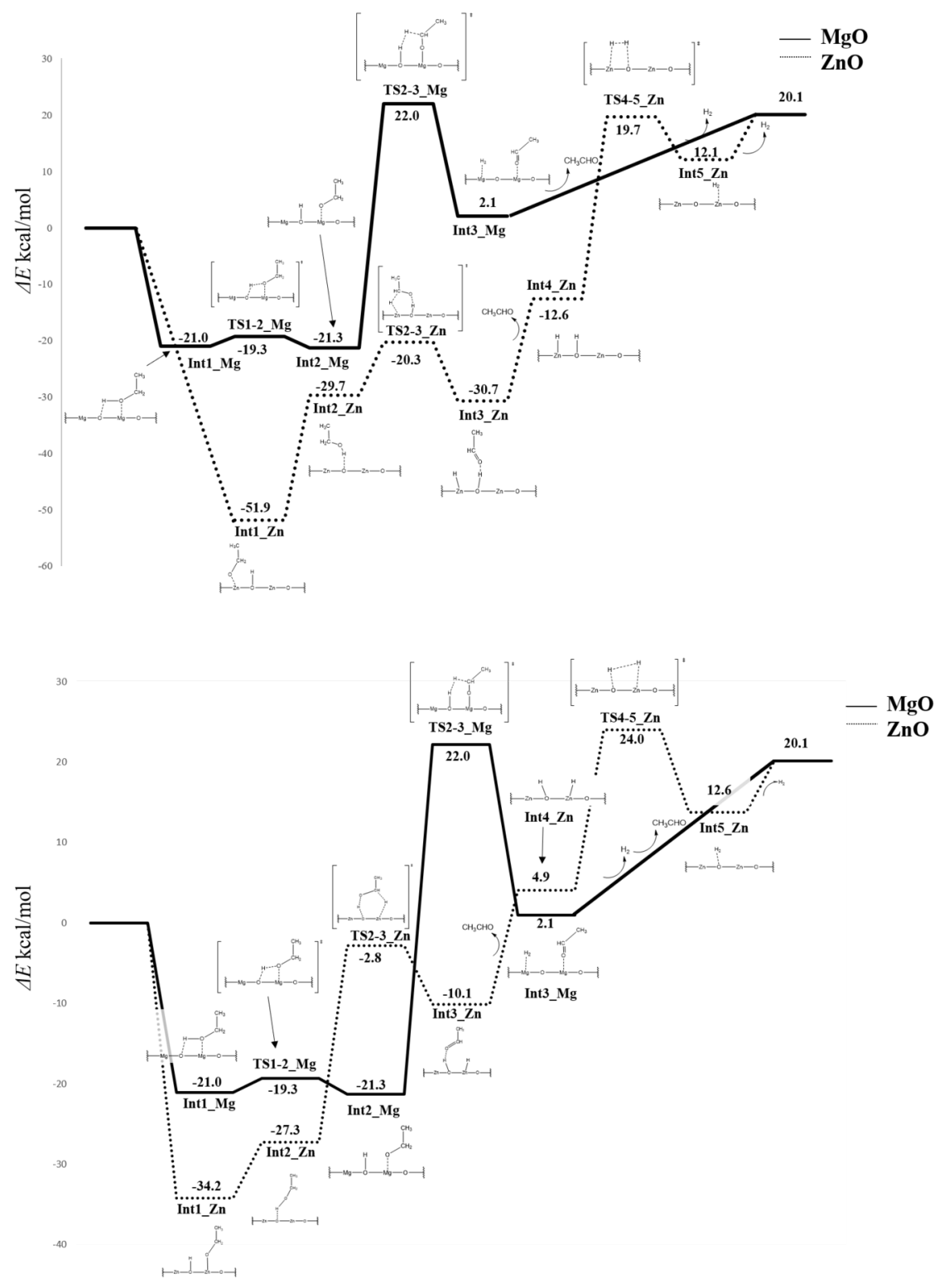

Figure 4. PESs for the formation of acetaldehyde from ethanol catalyzed by $\mathrm{MgO}$ or $\mathrm{ZnO}$.

Among possible adsorption sites, we first considered a terrace site. A first step of the formation in this case is Int1 $\mathrm{Mg}$ followed by the transfer of a $\mathrm{H}$ atom of the $\mathrm{OH}$ group to the $\mathrm{MgO}$ cluster that leads to Int2 $\mathbf{M g}$ whose details are shown in Fig. 4. As a result of TS1-2_Mg , ethanol is now converted to ethoxide $\left(\mathrm{CH}_{3} \mathrm{CH}_{2} \mathrm{O}^{-}\right)$. The computed energy barrier for TS1-2_ $\mathbf{M g}$ is $1.7 \mathrm{kcal} / \mathrm{mol}$ implying that this hydrogen atom transfer is virtually barrierless. OnceInt2_Mg is produced, the reaction can proceed via two different routes: 1) direct interaction of the $\mathrm{H}$ atom transferred to the $\mathrm{MgO}$ cluster, with one $\mathrm{H}$ of the methyl group of ethanol and consequent formation of acetaldehyde and an $\mathrm{H}_{2}$ molecule,Int3_Mg via TS2-3_Mg ; and 2) a stepwise mechanism in which the $\mathrm{H}$ atom of the methyl group is first transferred to the cluster, which leads to the formation of acetaldehyde. Both mechanisms have been explored revealing that the former is the only possible one when the $\mathrm{MgO}$ catalyst is used, even though a very high energy barrier corresponding to $43.3 \mathrm{kcal} / \mathrm{mol}$ is computed. Desorption of $\mathrm{H}_{2}$ molecule and acetaldehyde from Int3_Mgregenerated the catalyst. 
When the Mg-apical case is considered, no TS related to the first $\mathrm{H}$ transfer has been found, which indicates that ethanol dehydrogenation is not likely to occur at the Mg-apical site of the cluster. Considering the O-apical case, adsorption of ethanol occurs in a dissociative manner. Our attempts to locate a TS that leads to the formation of acetaldehyde at the O-apical site were also unsuccessful.

When the same reaction occurred on the $\mathrm{ZnO}$ cluster, the dissociative adsorption of ethanol takes place also on the terrace site, leading to the formation of Int1 $\mathbf{Z n}$, the energy of which is computed to be exothermic by $-34.2 \mathrm{kcal} / \mathrm{mol}$. The energetics of Int1_ $\mathbf{Z n}$ is larger than that of Int2_ $\mathbf{M g O}$, whose result correlates with the result of $\mathrm{NH}_{3}$ adsorption on the clusters described above, stressing the strong Lewis acidic nature of $\mathrm{Zn}$ in the $\mathrm{ZnO}$ cluster. The next step of the dehydrogenation is the $\alpha-\mathrm{H}$ atom transfer from ethoxide to the cluster. In the case of $\mathrm{ZnO}$, our attempt to search for a TS that corresponds to $\mathbf{T S 2 - 3} \mathbf{M g}$, a reaction that the adsorbed $\mathrm{H}$ atom on the cluster abstracts the $\alpha$-hydrogen atom of ethoxide, was unsuccessful. According to our computation, ethanol dehydrogenation catalyzed by $\mathrm{ZnO}$ occurs via TS2-3_Zn (Fig. 4). Before the TS occurrence, another intermediate, Int2_Zn is formed, where in case of $\mathbf{I n t 2} \mathbf{Z} \mathbf{Z n}$, the $\boldsymbol{\alpha}-\mathrm{H}$ is pointing to the $\mathrm{Zn}$ atom and the $\mathrm{O}-\mathrm{H}$ bond of ethanol is re-formed. As described in Fig. 4, two $\mathrm{H}$ atoms are simultaneously transferred to $\mathrm{ZnO}$ atTS2-3_Zn , where one is transferred to $\mathrm{Zn}$ and another to O. Such a TS is also found in ethanol dehydrogenation catalyzed by $\mathrm{Al}_{2} \mathrm{O}_{3} \cdot{ }^{[46]}$ Since the Lewis acidity of $\mathrm{Al}$ in $\mathrm{Al}_{2} \mathrm{O}_{3}$ is very strong, ${ }^{[47]}$ it is implied that the occurrence of the simultaneous $\mathrm{H}$ atom transfer, which is not observed in $\mathrm{MgO}$-catalyzed ethanol dehydrogenation, is associated with the strong Lewis acidity of the metal oxides. The energetics of TS2-3_Zn is $24.5 \mathrm{kcal} / \mathrm{mol}$ above $\mathbf{I n t 2} \mathbf{Z n}$ and $31.4 \mathrm{kcal} / \mathrm{mol}$ above Int1_Zn . Such values are lower than that of the ethanol dehydrogenation barrier catalyzed by $\mathrm{MgO}$ to some extent. As such, our computational results indicate that acetaldehyde production occurs more easily on the $\mathrm{ZnO}$ cluster. Int3_Zn corresponds to an intermediate where acetaldehyde, the final product of ethanol dehydrogenation, is adsorbed on the protonic $\mathrm{H}$ atom bonded to $\mathbf{Z n O}$. Int3_Zn is followed byInt4_Zn , which is generated upon desorption of acetaldehyde. It is seen in Fig. 4 that the energy barrier (TS3-4_Zn, $19.1 \mathrm{kcal} / \mathrm{mol}$ ) is required upon $\mathrm{H}_{2}$ molecule formation.Int5_Zn can be described as a hydrogen molecule adsorbed on $\mathrm{ZnO}$, where its desorption re-generates the catalyst. Overall ethanol dehydrogenation is endothermic by 20.1 $\mathrm{kcal} / \mathrm{mol}$.

\section{Aldol condensation}

The next step of ethanol-to-butadiene conversion is the aldol condensation of two acetaldehyde molecules to form 3-hydroxybutanal, followed by dehydration to produce crotonaldehyde. PESs for aldol condensation, obtained from DFT calculations, were shown in Fig. 5.

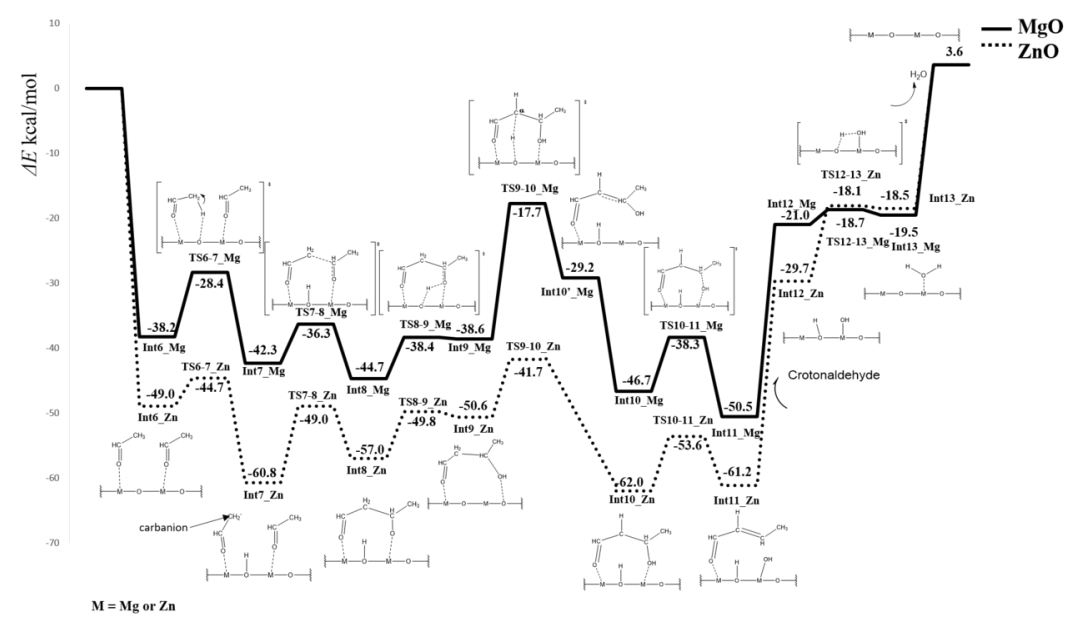

Figure 5. PESs for the formation of crotonaldehyde from two acetaldehyde molecules catalyzed by $\mathrm{MgO}$ or $\mathrm{ZnO}$. 
Acetaldehyde molecules formed in the previous step adsorbed on the metal oxide whose energetics are shown in Fig. 5 along with the PESs of the reaction. Similar to the adsorption of ethanol, the adsorption energy of acetaldehyde was larger for $\mathrm{ZnO}$ than for $\mathrm{MgO}$ (see energetics of Int6_Mg and Int6_Zn ). This result also reflects the strong Lewis acidic nature of the $\mathrm{Zn}$ atom in $\mathrm{ZnO}$. The next step of aldol condensation is carbanion formation, which results from proton transfer from the methyl group of acetaldehyde to the metal oxide cluster, where the relevant TS is schematically described in Fig. 5 (TS6-7_Mg, TS6-7_Zn ). The barrier heights of the proton transfer were computed to be $9.8 \mathrm{kcal} / \mathrm{mol}$ and $4.3 \mathrm{kcal} / \mathrm{mol}$ for $\mathrm{MgO}$ and $\mathrm{ZnO}$, respectively. The smaller barrier height of $\mathrm{ZnO}$ implies the strong Lewis basic nature of the $\mathrm{O}$ atom in $\mathrm{ZnO}$. The resulting carbanion can now attack the $\mathrm{C}$ atom of the carbonyl group of the neighboring acetaldehyde to formInt8_M ( $\mathbf{M}=\mathbf{M g}$ or $\mathbf{Z n})$ via $\mathbf{T S 7 - 8} \mathbf{M}$. The associated barrier heights for this step were computed to be 6.0 and $11.8 \mathrm{kcal} / \mathrm{mol}$ for $\mathrm{MgO}$ and $\mathrm{ZnO}$, respectively. The calculated atomistic charge of the carbanion was -0.79 e for $\mathrm{MgO}$ and -0.74 e for $\mathrm{ZnO}$, which indicated the carbanion on $\mathrm{MgO}$ was more anionic. The lower barrier height of the $\mathrm{C}-\mathrm{C}$ bond formation step due to $\mathrm{MgO}$ catalyst thus was contributed from the larger anionic nature of carbanion on $\mathrm{MgO}$. The $\mathrm{C}-\mathrm{C}$ bond formation reaction in aldol condensation forms Int8_M(Fig. 5) and the resulting intermediate now had four $\mathrm{C}$ atoms, which constitutes the basic skeleton of butadiene. After the formation ofInt8_M , the proton on the metal oxide is transferred back to the O atom via TS8-9_M to form 3-hydroxybutanal (Int9_M ). The barrier for this step was very low (Fig. 5). We note that the energetics of Int6_M and Int9_M , which is the final product of aldol condensation, are virtually identical, i.e., less than $2 \mathrm{kcal} / \mathrm{mol}$, regardless of the catalysts. This result implies that the thermodynamic driving force that leads to the formation of Int6_M from $\mathbf{I n t 9} \mathbf{M}$ is not sufficient.

To form crotonaldehyde, dehydration of 3-hydroxybutanal should occur as the next step. TS9-10_M in Fig. 5 corresponds to $\mathrm{C}-\mathrm{H}$ bond cleavage occurring at the $\alpha-\mathrm{C}$ of 3 -hydroxybutanal. The resulting intermediate is Int10_M . In the case of $\mathrm{MgO}$, we could locateInt10' $\mathbf{M g}$ where the hydroxy group is not bonded to the catalyst, followed by the formation of Int10_Mg . The barrier height of TS9-10_M differs by the involved catalysts as shown in Fig. 5. In the case of $\mathrm{MgO}$, the barrier height was computed to be $20.9 \mathrm{kcal} / \mathrm{mol}$, whereas that of $\mathrm{ZnO}$ is 8.9. Thus, $\mathrm{ZnO}$ is a more effective catalyst for this step. After the formation of Int10_M , a reaction proceeds to form crotonaldehyde via TS10-11_M , which corresponds to the TS of the $\mathrm{OH}$ group transfer to the catalyst, followed by the formation of Int11_M . The barrier height of this elementary reaction by $\mathrm{MgO}$ was computed to be $8.4 \mathrm{kcal} / \mathrm{mol}$ and that of $\mathrm{ZnO}, 8.4 \mathrm{kcal} / \mathrm{mol}$. Int11_M is an intermediate where crotonaldehyde, proton and the $\mathrm{OH}$ group are adsorbed on the catalyst where the latter two groups are chemically adsorbed. Desorption of crotonaldehyde leads to the formation of Int12_M as described in Fig. 5. After desorption, water-molecule formation on the catalyst and water desorption where the processes finally regenerate the catalysts. The PESs in Fig. 5 show that the energetics ofInt12_Zn is

lower than that of Int13_Zn implying that $\mathrm{H}_{2} \mathrm{O}$ is easily dissociated into $\mathrm{H}$ and $\mathrm{OH}$ on $\mathrm{ZnO}$. The aldol condensation followed by the dehydration is endothermic by $3.6 \mathrm{kcal} / \mathrm{mol}$.

\section{Crotonaldehyde reduction}

Reduction of crotonaldehyde to crotyl alcohol can be performed by $\mathrm{H}$ atoms from ethanol in the MeerweinPondorf-Verley (MPV) reduction, where, in the reduction process, ethanol acts as a donor of $\mathrm{H}$ atoms to crotonaldehyde. 


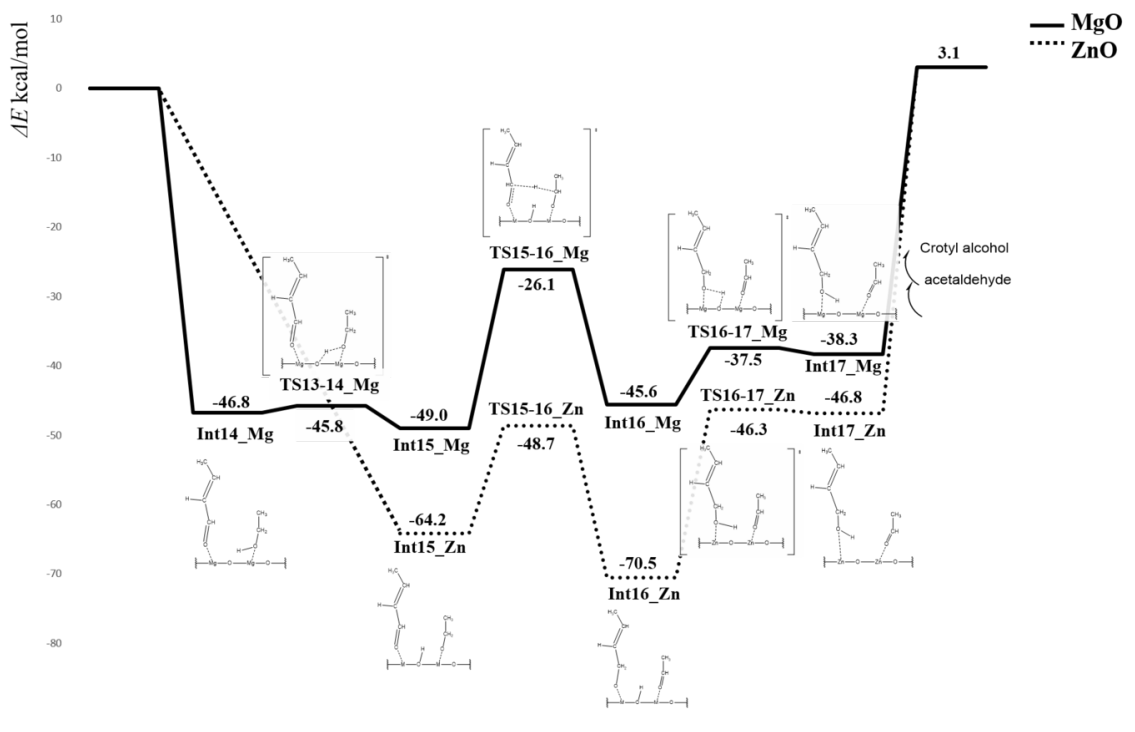

Figure 6. PESs for MPV reduction catalyzed by $\mathrm{MgO}$ or $\mathrm{ZnO}$.

The PESs of the MPV reduction by $\mathrm{MgO}$ or $\mathrm{ZnO}$ are shown in Fig. 6. As a first step of the MPV reduction, crotonaldehyde and ethanol are adsorbed on the catalyst. The energetics of Int14_Mg was computed to be $-46.8 \mathrm{kcal} / \mathrm{mol}$. Similar to the ethanol dehydrogenation, the proton from the $\mathrm{OH}$ group of ethanol is easily transferred to the catalyst where the barrier height was computed to be $1 \mathrm{kcal} / \mathrm{mol}$. As noted, in the case of $\mathrm{ZnO}$, ethanol is adsorbed in a dissociative manner. The PESs in Fig. 6 show that the energetics of Int15_Zn was $-64.2 \mathrm{kcal} / \mathrm{mol}$, which indicates the stronger basicity of ZnO. The second step of the MPV reduction is $\mathrm{H}$ atom abstraction of crotonaldehyde from the neighboring ethanol, whose TS corresponds to TS15_16_M(M = Mg , Zn ). The barrier height associated with this reaction were computed to be 22.9 and $15.5 \mathrm{kcal} / \mathrm{mol}$ for $\mathrm{MgO}$ and $\mathrm{ZnO}$, respectively. The barrier was higher by $7.4 \mathrm{kcal} / \mathrm{mol}$ for $\mathrm{MgO}$ than for $\mathrm{ZnO}$. The next step of the MPV reduction is a proton transfer to the $\mathrm{O}$ atom of crotonaldehyde as shown in Fig. 6. For $\mathrm{MgO}$, the computed barrier height for this reaction was $8.1 \mathrm{kcal} / \mathrm{mol}$. As a result of the proton transfer, Int7_Mg is formed, where its energetics lies above that of Int16_Mg , indicating the endothermic nature of the reaction. The energetics of Int16_Zn was computed to be $-70.5 \mathrm{kcal} / \mathrm{mol}$, remarkably larger than that of Int16_Mg. The proton transfer to the $\mathrm{O}$ atom requires an energy barrier of $24.2 \mathrm{kcal} / \mathrm{mol}$ in the case of $\mathrm{ZnO}$ as shown in Fig. 6. It is notable that the corresponding barrier height due to $\mathrm{MgO}$ is $8.1 \mathrm{kcal} / \mathrm{mol}$, whose value is much lower than that due to $\mathrm{ZnO}$. It is obvious that such a larger barrier by $\mathrm{ZnO}$ arises from the strong Lewis basicity of $\mathrm{O}$ in $\mathrm{ZnO}$. This type of reaction is an example of a reaction where the strong Lewis basicity affects the catalytic performance in a negative manner. To gain information on structural aspects of $\mathbf{I n t 1 6} \mathbf{M}(\mathbf{M}=\mathbf{M g}, \mathbf{Z n})$ we show their molecular structure in Fig. 7 . After this intermediate, the proton (labeled $\mathbf{P}$ in the figure) which was bonded to the catalyst, was transferred to the crotyl alcohol moiety viaT16-17_M ( $\mathrm{M}=\mathrm{Mg}$ or $\mathrm{Zn})$. The distance between the proton and the neighboring crotyl alcohol is shown in Fig. 7 where the distance of $\mathrm{MgO}(1.86 \AA)$ was shorter than that of $\mathrm{ZnO}(2.11 \AA)$. The atomistic distance between the proton and the closest $\mathrm{O}$ atom in the catalyst was computed to be 0.99 and $0.97 \AA$ for $\mathrm{MgO}$ and $\mathrm{ZnO}$, respectively. All such results imply that transfer of proton from the catalyst should occur more easily on $\mathrm{MgO}$.

Figure 7. Structure of Int16_Mg andInt16_Zn.

The energetics of Int17_Zn is endothermic by $23.7 \mathrm{kcal} / \mathrm{mol}$ with respect to Int16_Zn . After the formation of Int17_Zn or Int17_Mg, desorption of crotyl alcohol and acetaldehyde occurs to regenerate the catalysts. The final state of the reaction lies $3.1 \mathrm{kcal} / \mathrm{mol}$ above the reference state.

Crotyl alcohol dehydration 
The final part of the overall mechanism is the dehydration of crotyl alcohol to ultimately produce butadiene.

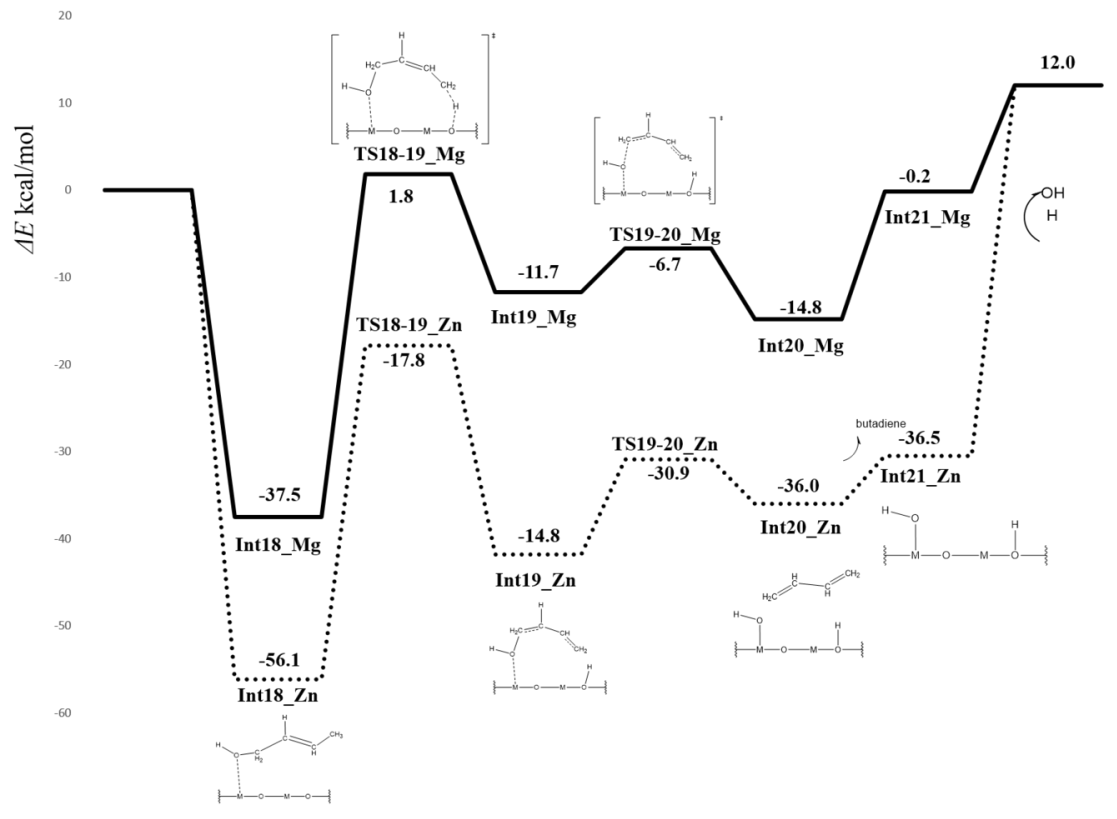

Figure 8. PESs for the 1,3-butadiene production catalyzed by $\mathrm{MgO}$ or $\mathrm{ZnO}$. Dehydration of crotyl alcohol consists of two elementary reactions. PESs for the dehydration is shown in Fig. 8. The first one is the transfer of a $\mathrm{H}$ atom from the terminal methyl group of crotyl alcohol to the $\mathrm{O}$ atom of the catalyst as shown in Fig. 8. The barrier heights of this step were computed to be 39.3 and $38.3 \mathrm{kcal} / \mathrm{mol}$ for $\mathrm{MgO}$ and $\mathrm{ZnO}$, respectively. The next step of dehydration is the $\mathrm{C}-\mathrm{O}$ bond cleavage leading to the $\mathrm{OH}$ group transfer to the Lewis acidic site of the catalyst, which corresponds to TS19-20_M(M= Mg, Zn $)$. MgO is more efficient in this step $(5.0 \mathrm{kcal} / \mathrm{mol})$ than $\mathrm{ZnO}(16.1 \mathrm{kcal} / \mathrm{mol})$. Int20_M $(\mathbf{M}=\mathbf{M g}, \mathbf{Z n})$ represents the intermediate where butadiene is adsorbed on top of the catalyst. Desorption of butadiene leads to the formation of Int21_M ( $\mathbf{M}=\mathbf{M g}, \mathbf{Z n})$. The $\mathrm{OH}$ and $\mathrm{H}$ which were adsorbed on the catalyst were desorbed leading to the regeneration of the catalysts. The dehydration is endothermic by $12.0 \mathrm{kcal} / \mathrm{mol}$. Summary of main reaction Table 1 lists the highest barriers heights of each step. The highest barrier for ethanol-to-butadiene conversion by $\mathrm{MgO}$ occurs at the ethanol dehydrogenation step. This result reflects the lower acidity of $\mathrm{MgO}$. The barrier heights of other steps were lower than that of ethanol dehydrogenation, which implies that an admixture of catalysts having a higher ethanol dehydrogenation activity with $\mathrm{MgO}$ should improve the overall performance of ethanol-to-butadiene conversion. Table 1. Summary of highest barrier heights $(\mathrm{kcal} / \mathrm{mol})^{a}$

\begin{tabular}{|c|c|c|c|c|}
\hline & Type of reactions & Type of reactions & Type of reactions & Type of reactions \\
\hline & Ethanol dehydroge & Aldol condensation ${ }^{b}$ & MPV reduction & ol dehydration \\
\hline $\mathrm{IgO}$ & 43.3 & 20.9 & 22.9 & 39.3 \\
\hline $\mathrm{ZnO}$ & $24.5^{c}$ & 11.8 & 24.2 & 38.3 \\
\hline
\end{tabular}

${ }^{a}$ Only the highest barrier for each reaction is shown. ${ }^{b}$ Includes dehydration of 3-hydroxybutanal. ${ }^{c} 31.4$ $\mathrm{kcal} / \mathrm{mol}$, if the barrier is calculated from Int1_Zn. The barrier height regarding the $\mathrm{H}_{2}$ molecule formation was not considered. In the case of $\mathrm{ZnO}$, the computation showed that ethanol dehydrogenation occurs more easily in comparison $\mathrm{MgO}$ where such a result is in line with an experimental study which reports that the introduction of $\mathrm{Zn}$ into catalysts such as $\mathrm{MgO}_{2} / \mathrm{SiO}_{2}$ or talc enhances the catalytic activity for ethanol 
dehydrogenation. ${ }^{[48]} \mathrm{ZnO}$ appears to be a very good catalyst for aldol condensation and the following dehydration, the barrier of which was about half that of $\mathrm{MgO}$. On the other hand, ZnO's performance as a catalyst for the MPV reduction is slightly worse than that of MgO. Both oxides show virtually identical barrier height for crotyl alcohol dehydration. Side reactions One of the major undesired side reactions of ethanol-to-butadiene conversion is the formation of ethylene via ethanol dehydration. ${ }^{[1]}$ Indeed, metal oxides have been used for ethanol dehydration catalysts. ${ }^{[49,50]}$ One study reported that the Lewis acidity of metal oxides affects the catalytic performance of the dehydration. ${ }^{[50]}$ Dehydration of alcohol occurs via either an E1 or E2-type elimination reaction; according to a previous DFT study on the dehydration reaction over $\mathrm{Al}_{2} \mathrm{O}_{3}$, an E2 reaction is favored. ${ }^{[49]} \mathrm{PESs}$ for the dehydration of ethanol occurred via the E2 mechanism for $\mathrm{ZnO}$ and the $\mathrm{E} 1$ mechanism for $\mathrm{MgO}$ are shown in Fig. 9. While $\mathrm{MgO}$ follows the $\mathrm{E} 1$ mechanism, the energetics of the intermediate (INT2_Mg_Dehydration) is virtually identical to that of TS1_Mg_Dehydration, implying that the reaction mechanism is similar to that of the E2 mechanism. The computed barrier height was 40.5 and $38.9 \mathrm{kcal} / \mathrm{mol}$ for $\mathrm{ZnO}$ and $\mathrm{MgO}$, respectively. Also, the energetics of TS2_Mg_Dehydration was 41.9 $\mathrm{kcal} / \mathrm{mol}$ above that of INT1_Mg_Dehydration. This result indicated that the dehydration occurs more easily using ZnO as a catalyst. As the TS cartoon (TS_Zn_Dehydration) in Fig. 9 shows, the dehydration of ethanol via the E2 mechanism included the $\mathrm{C}-\mathrm{O}$ bond and the $\mathrm{C}-\mathrm{H}$ bond cleavage, where the former occurs at the Lewis acidic site and the latter at the Lewis basic site. Obviously, the strong Lewis acidity and basicity of $\mathrm{ZnO}$ cause the side reaction to occur more easily in comparison with MgO.Figure 9. PESs for ethylene production via dehydration of ethanol catalyzed by $\mathrm{MgO}$ or $\mathrm{ZnO}$. ( $\mathrm{M}=\mathrm{Mg}, \mathrm{Zn}$ ) In addition, the dehydration, e.g., the 3-hydroxybutanal dehydration (Fig. 5) results in the attachment of the $\mathrm{OH}$ group on the cluster (seeInt12_Zn or Int12_Mg in Fig. 5) where the OH groups can act as Brøntsed base sites. Thus, we further investigated the dehydration of ethanol on Brøntsed acid/base sites.Figure 10. PESs for ethylene production via dehydration of ethanol on Brøntsed base site. ( $\mathrm{M}=\mathrm{Mg}, \mathrm{Zn})$ Fig. 10 shows that PESs for dehydration of ethanol considering that water was already adsorbed in a dissociative manner as Hhwafffwathe $\mathrm{OH}$ group and $\mathrm{H}$ on catalyst. INT1_Brønsted is a complex on which the $\mathrm{OH}$ group and $\mathrm{H}$ are chemically adsorbed on the catalysts; ethanol is also adsorbed on the catalyst. The OH group of ethanol interacts with the metal atom of the metal oxide catalyst. The computed barrier heights of the dehydration were 39.5 and $43.3 \mathrm{kcal} / \mathrm{mol}$ for $\mathrm{ZnO}$ and $\mathrm{MgO}$, respectively, which are higher than the dehydration at the Lewis acid/base sites. Moreover, as shown in Fig. 10, the energetics of the product (INT2_Brønsted) is higher than that of reactant (INT1_Brønsted), which is in contrast to the dehydration at the Lewis acid/base site. As such, the dehydration that involves the Brøntsed base site is not preferred compared with the dehydration on Lewis acid/base sites. Compared with the ethanol dehydrogenation (see the PESs Fig. 4 ), $\mathrm{ZnO}$ is a better catalyst for dehydrogenation whereas $\mathrm{MgO}$ favors dehydration over dehydrogenation because the barrier for the dehydration is lower than that for dehydrogenation. Effects of Lewis acidity and basicityDetails of the PESs of each of the elementary reactions of ethanol-to-butadiene conversion have been discussed up to this point. Now we discuss the barrier heights of the elementary reactions in conjunction with the Lewis acidity/basicity of the metal oxide. One of the most notable features affected by the Lewis acidity/basicity is ethanol dehydrogenation because, as noted, it depends strongly on the metal's Lewis acidity. As the result of DFT calculations discussed in the previous section indicate, the $\mathrm{Mg}$ atom in $\mathrm{MgO}$ does not have sufficient Lewis acidity to facilitate the C-H bond cleavage corresponding to the $\alpha-\mathrm{H}$ transfer from ethanol. The C-H bond cleavage is also found in other reactions during ethanol-to-butadiene conversion. For example, TS9-10_M ( $\mathrm{M}=\mathrm{Mg}$ or Zn) shown in Fig. 5 andTS18-19_M ( $\mathrm{M}=\mathrm{Mg}$ or $\mathrm{Zn}$ ) (Fig. 8) also correspond to the TS of the $\mathrm{C}-\mathrm{H}$ bond cleavage and the latter occurs on the Lewis basic site. For this $\mathrm{C}-\mathrm{H}$ bond cleavage, the performance of $\mathrm{ZnO}$ as a catalyst is better than that of $\mathrm{MgO}$, which correlates with the stronger Lewis basicity of the $\mathrm{O}$ atoms of $\mathrm{ZnO}$. By contrast, the transfer of the $\mathrm{OH}$ group, which includes the C-O bond cleavage, appears to occur more easily on MgO. An example isTS19-20_M ( $M=M g$ or Zn). Associated barrier heights are lower for $\mathrm{MgO}$-catalyzed reactions than for $\mathrm{ZnO}$ catalyzed reactions of TS19-20_M.Figure 11. Structure of Int19_Mg andInt19_Zn.

To investigate its origin, we present the molecular structure ofInt19_Mg and Int19_Zn , whose details are shown in Fig. 11 along with some structural parameters. As mentioned above, these intermediates are followed by TS19-20_M ( $\mathrm{M}=\mathrm{Mg}$ or Zn), which corresponds to the TS of the C-O bond cleavage leading to 
butadiene formation. As shown in Fig.11, the distance between the terminal carbon atom and the closest metal $(\mathrm{Mg}$ or $\mathrm{Zn})$ atom was computed to be longer forInt19_Mg than for Int19_Zn $(2.22 \AA$ for $\mathrm{MgO}$, $2.03 \AA$ for $\mathrm{ZnO}$ ). This result also reflects the strong Lewis acidity of the $\mathrm{Zn}$ atom in the $\mathrm{ZnO}$ cluster. Also, the distance between the oxygen atom of the $\mathrm{OH}$ group and the neighboring metal atom was predicted to be $1.90 \AA$ and $2.18 \AA$ for $\mathrm{MgO}$ and $\mathrm{ZnO}$, respectively. As such, the shorter $\mathrm{O}-\mathrm{Mg}$ distance implies that the transfer of the $\mathrm{OH}$ group to the catalyst occurs more easily on $\mathrm{MgO}$ than $\mathrm{ZnO}$. Moreover, DFT calculations predicted that the bond distance $(4.08 \AA)$ of $\mathrm{Zn}_{1}-\mathrm{Zn}_{2}$ is longer than that $(3.76 \AA)$ of $\mathrm{Mg}_{1}-\mathrm{Mg}_{2}$. Such a result indicates that, structurally, the $\mathrm{Mg}_{1}-\mathrm{Mg}_{2}$ distance is similar to the molecular size of crotonaldehyde. Thus, the terminal $\mathrm{C}$ atom and the $\mathrm{O}$ atom of the $\mathrm{OH}$ group of crotonaldehyde can be simultaneously bonded to the catalyst in the case of $\mathrm{MgO}$. In contrast, the $\mathrm{Zn}_{1}-\mathrm{Zn}_{2}$ distance is longer than the molecular size of crotonaldehyde, which hinders the simultaneous bonding of the $\mathrm{OH}$ group and the terminal carbon of crotonaldehyde to the catalyst. Considering the above results, it could be reasonable to conclude that the lower $\mathrm{OH}$ transfer barrier height due to $\mathrm{MgO}$ arises from the structural mismatch between the adsorbate and the catalyst.

The ethanol-to-butadiene conversion reaction is very complex, being composed of series of elementary reactions. Depending on the nature of each elementary reaction, the Lewis acidity or basicity of metal oxide catalyst affects the performance of the catalyst in a positive or negative manner, as discussed above. According to our DFT calculations, most energy demanding process in the ethanol-to-butadiene conversion catalyzed by $\mathrm{MgO}$ was ethanol dehydrogenation and this step was strongly influenced by the Lewis acidity of the catalyst, of which result is, to some extent, in line with a recent study on ethanol dehydrogenation catalyzed by $\mathrm{MgO}-\mathrm{SiO}_{2} \cdot{ }^{[52]} \mathrm{DFT}$ calculation showed that $\mathrm{ZnO}$ is a better catalyst in this step, where such a performance arisen from its stronger Lewis acidity. Moreover, another important aspect of $\mathrm{ZnO}$ is that the catalyst favors ethanol dehydrogenation over the dehydration, whose feature was opposite to that of $\mathrm{MgO}$.

\section{Concluding Remarks}

In the present paper, we explored the complex reaction mechanism of ethanol-to-butadiene conversion reaction on two metal oxides, $\mathrm{MgO}$ and $\mathrm{ZnO}$ using DFT. PESs of all elementary reactions associated with the conversion reaction were computed including relevant TSs and intermediates. We found that ethanol dehydrogenation, which was the first step of the conversion reaction, was very energy demanding compared with other steps when $\mathrm{MgO}$ was used as a catalyst. DFT calculations showed that $\mathrm{ZnO}$ was a better catalyst for most of elementary reactions involved in the conversion reaction. Especially, its better ability as an ethanol dehydrogenation catalyst was worth mentioning, where it resulted from the strong Lewis acidic character of $\mathrm{ZnO}$. Moreover, the performance of $\mathrm{ZnO}$ as an aldol condensation catalyst was very good since the highest barrier of aldol condensation catalyzed by $\mathrm{ZnO}$ was $11.8 \mathrm{kcal} / \mathrm{mol}$. In aldol condensation, the Lewis acidic and basic sites of catalyst participated in the reaction, so that $\mathrm{ZnO}$ shows a better performance as a catalyst in comparison with $\mathrm{MgO}$. For the MPV reduction, our calculation showed that $\mathrm{MgO}$ was a better catalyst for this step. Butadiene formation through crotyl alcohol dehydration did not depend much on the catalysts considered in the present study while this step was predicted to be the rate determining step of ZnO catalyzed reaction. DFT calculations predicted ethanol dehydration, one of the undesired side reactions, occurred more easily on $\mathrm{ZnO}$ than on $\mathrm{MgO}$ at Lewis acid/base sites of the catalyst. Ethanol dehydration on Brøntsed base site was not likely to occur since the barriers were higher than those of Lewis acid/base site. Although $\mathrm{ZnO}$ 's barrier height for ethylene formation was lower than that of $\mathrm{MgO}$, the barrier height of ethylene formation was higher than that of acetaldehyde formation in the case of $\mathrm{ZnO}$. Thus, one can suggest that the use of $\mathrm{ZnO}$ should enhance selectivity for acetaldehyde formation over ethylene formation, which also affects yield of butadiene formation. In view of Lewis acidity or basicity, the use of metal oxide catalyst having strong Lewis acidity or basicity can lower several elementary reactions in the conversion reaction. However, as demonstrated, such a catalyst is likely to increase the production of undesired side products. Thus, the optimal strength (not too strong or not too weak) of Lewis acidity and basicity for optimal performance of the catalyst could be suggested, which requires more extensive screening of catalysts.

\section{Acknowledgement}


This study has been supported by a project JPNP16010, commissioned by the New Energy and Industrial Technology Development Organization (NEDO).

\section{References}

1. E. V. Makshina, M. Dusselier, W. Janssens, J. Degrève, P. Jacobs, B. Sels. Chem. Soc. Rev. 2014 , 43 , 7917-7953.

2. C. Angelici, B. M. Weckhuysen, P. C. A. Bruijnincx, ChemSusChem, 2013 , 6 , 1595-1614.

3. V. L. Sushkevich, I. I. Ivanova, Appl. Catal. B. 2017 ,215, 36-49.

4. O. V. Larina, P. I. Kyrienko, S. O. Soloviev, Catal. Lett.2015 , 145 , 1162-1168.

5. G. M. C. González, R. Murciano, A. L. Villanueva Perales, A. Martínez, F. Vidal-Barrero, M. Campoy, Appl. Catal. A. $2019,570,96-106$.

6. W. E. Taifan, J. Baltrusaitis, J. Phys. Chem. C. 2018 ,122 , 20894-20906.

7. M. Zhang, M. Gao, C. Jianyue, Y. Yu, RSC Adv. , 2015 ,5 , 25959-25966.

8. C. Angelici, M. E. Z. Velthoen, B. M. Weckhuysen, P. C. A. Bruijnincx, Catal. Sci. Technol. 2015 , 5 , 2869-2879.

9. M. D. Jones, C. G. Keir, C. Di Iulio, R. A. M. Robertson, C. V. Williams, D. C. Apperley, Catal. Sci. Technol. $2011,1,267-272$.

10. Y. Sekiguchi, S. Akiyama, W. Urakawa, A. Miyaji, K. Motokura, T. Baba,Catal. Commun., 2015, 68 , 20-24.

11. H. Niiyama, S. Morii, E. Echigoya, Bull. Chem. Soc. Jpn .,1972, 45, 655- 659.

12. V. N. Ipatiev, J. Prakt. Chem ., 1903, 2 , $67-70$.

13. J. Ostromislenskiy, J. Russ. Phys. Chem. Soc ., 1915 ,47 , 1472-1506.

14. S. V. Lebedev, British Patent 1929 , 331,402.

15. S. V. Lebedev, J. Gen. Chem ., 1933, 3, 698- 708.

16. S. V. Lebedev, Chem. -Ztg., $1936,60,313-316$.

17. W. J. Toussaint, J. T. Dunn, U. S. Patent $1944,2,357,855$.

18. W. J. Toussaint, J. T. Dunn, D. R. Jackson, Ind. Eng. Chem .,1974, 39 , 120-125.

19. W. M. Quattlebaum, W. J. Toussaint, J. T. Dunn, J. Am. Chem. Soc., 1947, 69 , 593-599.

20. H. E. Jones, E. E. Stahly, B. B. Corson, J. Am. Chem. Soc.1949 , 71 , 1822-1828.

21. Y. A. Gorin, M. I. Danilina, J. Gen. Chem ., $1948,18,1069-1075$.

22. S. K. Bhattacharyya, S. K., Sanyal, J. Catal ., 1967, 7, $152-158$.

23. S. Kvisle, A. Aguero, R. P. A. Sneeden (1988). Appl. Catal .,1988 , 43 , $117-131$.

24. A. Chieregato, J. V. Ochoa, C. Bandinelli, G. Fornasari, F. Cavani, M. Mella, ChemSusChem, 2015 , $8,377-388$.

25. D. Fan, X. Dong, Y. Yu, M. Zhang, Phys. Chem. Chem. Phys.2017, 19 , 25671-25681.

26. W. E. Taifan, T. Bučko, J. Baltrusaitis, J. Catal.2017 , 346 , 78-91.

27. M. Zhang, J. Zhuang, Y. Yu, Appl. Surf. Sci. 2018 ,458, 1026-1034.

28. X. Dong, J. Lu, Y. Yu, M. Zhang, Phys. Chem. Chem. Phys.2018, 20, 12970-12978.

29. T. Yan, W. Dai, G. Wu, S. Lang, M. Hunger, N. Guan, L. Li, ACS Catal. , 2018 , 8 , 2760-2773.

30. H. -J. Chae, T. -W. Kim, Y. -K. Moon, H. -K. Kim, K. -E. Jeong, C. -U. Kim, S. -Y. Jeong, Appl. Catal. B. $2014,150-151,596-604$.

31. M. Haertelt, A. Fielicke, G. Meijer, K. Kwapien, M. Sierka, J. Sauer,Phys. Chem. Chem. Phys. 2012 , $14,2849-2856$.

32. S. Goedecker, J. Chem. Phys. 2004, 120, 9911-9917.

33. A. H. Larsen, J. J. Mortensen, J. Blomqvist, I. E. Castelli, R. Christensen, M. Dulak, J. Friis, M. N. Groves, B. Hammer, C. Hargus, E. D. Hermes, P. C. Jennings, P. B. Jensen, J. Kermode, J. R. Kitchin, E. L. Kolsbjerg, J. Kubal, K. Kaasbjerg, S. Lysgaard, J. B. Maronsson, T. Maxson, T. Olsen, L. Pastewka, A. Peterson, C. Rostgaard, J. Schiøtz, O. Schütt, M. Strange, K. S. Thygesen, T. Vegge, L. Vilhelmsen, M. Walter, Z. Zeng, K. W. Jacobsen, J. Phys. :Condens. Matter. 2017, 29 , 273002.

34. We used HF/6-311G(d,p) level of theory for the global optimization to save the computational costs. Other parameters for the minima hopping algorithm, which is one of the global optimization techni- 
ques implemented in ASE, are followings: $T_{0}$ (initial molecular dynamics temperature) $=4000 \mathrm{~K}$, $E_{\text {diff }}($ initial energy acceptance threshold $)=0.5 \mathrm{eV}$.

35. Gaussian 16, Revision B.01, M. J. Frisch, G. W. Trucks, H. B. Schlegel, G. E. Scuseria, M. A. Robb, J. R. Cheeseman, G. Scalmani, V. Barone, G. A. Petersson, H. Nakatsuji, X. Li, M. Caricato, A. V. Marenich, J. Bloino, B. G. Janesko, R. Gomperts, B. Mennucci, H. P. Hratchian, J. V. Ortiz, A. F. Izmaylov, J. L. Sonnenberg, D. Williams-Young, F. Ding, F. Lipparini, F. Egidi, J. Goings, B. Peng, A. Petrone, T. Henderson, D. Ranasinghe, V. G. Zakrzewski, J. Gao, N. Rega, G. Zheng, W. Liang, M. Hada, M. Ehara, K. Toyota, R. Fukuda, J. Hasegawa, M. Ishida, T. Nakajima, Y. Honda, O. Kitao, H. Nakai, T. Vreven, K. Throssell, J. A. Montgomery, Jr., J. E. Peralta, F. Ogliaro, M. J. Bearpark, J. J. Heyd, E. N. Brothers, K. N. Kudin, V. N. Staroverov, T. A. Keith, R. Kobayashi, J. Normand, K. Raghavachari, A. P. Rendell, J. C. Burant, S. S. Iyengar, J. Tomasi, M. Cossi, J. M. Millam, M. Klene, C. Adamo, R. Cammi, J. W. Ochterski, R. L. Martin, K. Morokuma, O. Farkas, J. B. Foresman, and D. J. Fox, Gaussian, Inc., Wallingford CT, 2016.

36. A. D. Becke, J. Chem. Phys. $1993,98,5648-5652$.

37. C. Lee, W. Yang, R. G. Parr, Phys. Rev. B. 1988 ,37, 785-789.

38. S. H. Vosko, L. Wilk, M. Nusair, Can. J. Phys. 1980 ,58 , 1200-1211.

39. P. J. Stephens, F. J. Devlin, C. F. Chabalowski, M. J. Frisch,J. Phys. Chem. , 1994, 98 , 11623 11627.

40. K. Fukui, Acc. Chem. Res. 1981, 14, 363-368.

41. V. E. Henrich, P A. Cox, The Surface Science of Metal Oxides, Cambridge University Press, 2014. 42. W. E. Taifan, J. Baltrusaitis, J. Phys. Chem. C. 2018 ,122, 20894-20906.

43. S. A. S. Farias, E. Longo, R. Gargano, J. B. L. Martins, J. Mol. Model. 2013 , 19 , 2069-2078.

44. A. Aurox, A. Gervasini, J. Phys. Chem. $1990,94,6371-6379$.

45. M. M. Branda, A. H. Rodríguez, P. G. Belelli, N. J. Castellania,Surface Science, 2009 , 603 , 10931098.

46. Z. Fnag, Y. Wang, D. A. Dixon, J. Phys. Chem. C . 2015 ,119 , 23413-23421.

47. G. Busca, Phys. Chem. Chem. Phys. 1999, $1,723-736$.

48. Y. Hayashi, S. Akiyama, A. Miyaji, Y. Sekiguchi, Y. Sakamoto, A. Shiga, To-ru. Koyama, K. Motokura, T. Baba, Phys. Chem. Chem. Phys. 2016, $18,25191-25209$.

49. Z. Fang, Y. Wang, D. A. Dixon, J. Phys. Chem. C . 2015 ,119, 23413-23421.

50. M. Zhang, Y. Yu, Ind. Eng. Chem. Res. 2013 , 52, 9505-9514.

51. P. Kostestkyy, J. Yu, R. J. Gorte, G. Mpourmpakis, Catal. Sci. Technol. 2014 , 4 , 3861-3869.

52. H. T. Abdulrazzaq, A. R. Chokanlu, B. G. Frederick, T. J. Schwartz, ACS Catal. 2020 , 10 , 6318-6331. 